\title{
ENERGY TRANSITION OF THE BALTIC STATES: PROBLEMS AND SOLUTIONS
}

\author{
A. Sauhats ${ }^{*}$ Z. Broka, K. Baltputnis \\ Riga Technical University, Institute of Power Engineering \\ 12-k1 Azenes Str., Riga, LV-1048, LATVIA \\ *e-mail: antans.sauhats@rtu.Iv
}

The importance of the climate change problem is recognised by the governments of the overwhelming majority of the world's countries. To bring additional attention and enable more concrete action, in a number of countries and municipalities the issue has been declared a climate emergency. The need to solve this problem predetermines the task of replacing fossil energy sources with renewable alternatives. The process of the ongoing transformation is called energy transition. It includes transformation of all the energy-intensive sectors of economic activity: power generation, supply and consumption, heat generation and supply, electrification of transport, agriculture and households.

The main goal of the energy transition is obvious - it is necessary to reduce the emissions of carbon dioxide into the atmosphere. The main sources of energy used to achieve this goal in power generation are wind and solar energy. Even though the goal is unambiguously defined and the way to achieve it seems evident, it is already clear that a number of serious problems and obstacles have arisen. They are caused by the emergence of additional objectives that must be achieved and constraints that need to be satisfied in the process of the required transformations. Indeed, the transition should be carried out taking into account power system properties describing techno-economic efficiency, reliability, stability, adequacy, etc. This list can be expanded easily. It should be noted that the additional objectives are not less important than the overarching goal. Along with reducing emissions, it is also necessary to improve energy supply reliability, its availability and affordability for all the segments of the population as well as maintain the security of the energy supply infrastructure and processes.

Keywords: Energy transitions, FutureProof, INGRIDO, I-POWER, LAGAS, SecureGas, the Baltic States. 
The need to simultaneously achieve several goals leads to complex global tasks which can only be solved through the combined efforts of many countries in cooperation with technology developers and manufacturers, research institutions, generation companies, transmission and distribution network operators as well as the energy consumers, i.e., businesses and the general population. An important direction in tackling the problem is the increasing interconnection between various types of energy infrastructures and carriers (i.e., multienergy systems). However, at the same time, this solution also has the potential to exacerbate the problem by introducing additional issues. The energy supply process can be disrupted by malfunctions in communication systems, water supply, transport infrastructure, etc. Importantly, even shortterm power outages can cause huge economic losses arising from the stoppage of economic activity in cities and potentially even whole countries. Moreover, failure of interconnected energy supply infrastructure can lead to tragic consequences to human life, such as the recent failure of the Texas, power system aggravated by a notably rare occurrence of an intensive cold spell. However, such issues can be prevented by planning for the worst-case scenarios, even if their probabilities are very low.

In most of the world, the energy transition process is already in full swing. Dramatic changes have also taken place in the energy systems of the Baltic countries. Some of the most important developments in recent decades are summarised below:

- the operation of major power generation plants has been stopped or severely reduced (i.e., two units of the Elektrenai Complex have been put in reserve, and the oil-shale power plants in Narva are partly being phased-out);

- new power transmission lines have been built connecting the Baltic States to Finland, Sweden, and Poland;

- the Baltic countries have become part of the Nord Pool electricity market where most of the day-ahead and intraday trade takes place;

- combined cycle thermal power plants of significant capacity have been built or refurbished and put into operation;

- hundreds of renewable energy power plants have been put into operation (small hydroelectric power plants, biomass and biogas plants, wind and solar power plants);

- the operation of electricity and gas networks has been significantly strengthened. The control systems of energy supply infrastructure and facilities have been modernised, taking advantage of the rapid advancements in information and communication technologies.

However, in the process of these changes, the Baltic energy systems have only partially achieved their development goals: emissions are still overall high, and the Baltic energy system as a whole has become acutely deficient. In 2020, only $55 \%$ of the consumed electricity was generated by local power plants. To solve the problem of generation shortage, also taking into account the need to replace the existing fossil power plants, evidently, significant capacities of renewable energy power plants will be required in the near future. This challenge is compounded by the fact that an increase in electricity consumption in transport, households and industry is expected. 
Summarising the above, we can say that for the successful future development of energy supply in the Baltic countries, a significant number of problems need to be solved, some of which are addressed in this special issue of the Latvian Journal of Physics and Technical Sciences. A common feature of the articles presented in this issue of the Journal is that this research is partly or in full conducted within a number of projects of the Institute of Power Engineering of Riga Technical University with participation of partners from other scientific institutions and industry. The articles included in this issue show the preliminary or final results of several of the many tasks tackled within the framework of selected projects aimed at energy transition:

1. "Future-Proof Development of the Latvian Power System in an Integrated Europe (FutureProof)", project No. VPP-EM-INFRA-2018/1-0005;

2. "Innovative Smart Grid Technologies and their Optimization (INGRIDO)", project No. VPP-EM-INFRA-2018/10006;

3. "Trends, Challenges and Solutions of Latvian Gas Infrastructure Development (LAGAS)", project No. VPP-EMINFRA-2018/1-0003;

4. "Management and Operation of an Intelligent Power System (I-POWER)", project No. 1zp-2018/1-0066;

5. European Union's Horizon 2020 research and innovation programme under grant agreement No. 833017, project "SecureGas";

6. "Electrical Grid Design Methods and Tools, Considering Smart Technologies and Market Conditions" project No. No.1.1.1.2/VIAA/2/18/317.

In the next sections, the aims and main tasks of these projects are summarised, followed by brief introduction of the articles included in this special edition and their contribution to the project tasks.

\section{BRIEF DESCRIPTION OF THE PROJECTS}

\subsection{Future-Proof Development of the Latvian Power System in an Integrated Europe}

The main aim of the project is to foster sustainability and competitiveness of a smart and reliable Latvian energy system, promote its conformity to public interests and integration into the European energy system through detailed studies and modelling of the power system infrastructure, markets, risks and future development scenarios. To achieve this aim, a number of diverse tasks are addressed:

- definition and assessment of long-term scenarios for sustainable development of the Latvian power system up to 2050;

- modelling and simulations of electricity markets relevant for Latvia;

- Latvian power system risk assessment and development of recommendations for risk mitigation;

- $\quad$ energy poverty analysis in Latvia;

- preparation of recommendations to policy makers informed by the major project findings and results;

- development of databases, including the characteristics and indicators, historical and forecast time series important for the Latvian power system analysis and its future development scenario assessment. 


\subsection{Innovative Smart Grid Technologies and their Optimization}

The goal of the project is to assess the innovation and optimization potential in the Latvian power system and develop solutions for increased efficiency given the growing use of renewable and distributed energy sources, emergence of prosumers and other market development trends. To complete this project, the following is carried out:

- analysis of the current situation in terms of energy supply in Latvia and the forecast innovation trends up to 2050;

- identification of power system flexibility issues now and in the future, and devising measures to mitigate them, also taking advantage of such development trends as increasing efficiency

\subsection{Trends, Challenges and Solutions of Latvian Gas Infrastructure Development}

The aim of the project is to study the infrastructure of gas supply, storage and distribution as well as the market, risks and future development scenarios so as to develop solutions for improving the efficiency and reliability of the gas system operation. The tasks undertaken are related to:

- the Latvian natural gas transmission, distribution and liquefied natural gas production and transportation system development forecasts;

- the modelling of the gas network, ensur- of the building stock, distributed generation, aggregator operation, demand response, energy accumulation, development of smart grids and the emergence of prosumers;

- encouraging transition towards a smart grid ecosystem by developing optimized control strategies for consumer and prosumer aggregation, and by producing smart adaptive automation and protection methods for the grids of the future;

- development of guidelines for the assessment of energy supply infrastructure efficiency tailored for the Latvian case, and subsequent assessment of infrastructure inefficiencies.

\subsection{Management and Operation of an Intelligent Power System}

The main aim of the project is to increase the efficiency, reliability and sustainability of the power supply in Latvia. To achieve this aim, the following is performed:

- analysis and selection of small and micro-size energy generation plants and their control technologies: microCHPPs, heat pumps of various kinds, solar collectors, wind turbines and heat and electricity storage technologies are reviewed and selected for in-depth analysis along with methods, techniques and algorithms for their control;

- development of models of large, small, and micro-size energy prosumers with the aim of determining short-term and long-term production costs and other economic indicators; 
- providing new solutions addressing the need for optimal operation of power plants at market conditions;

- bringing an innovative solution to the market, facing future challenges regarding market development, and spreading the knowledge to as many sectors of the energy industry as possible.

\section{GLIMPSE INTO THE ARTICLES}

The articles presented in this special issue of the journal reflect the results of the research carried out within the framework of the above projects, showcasing both the outcomes of individual project tasks as well as the fruits of cross-project cooperation, whereby the researchers working in the different areas have identified opportunities for synergetic collaboration. The introductory article describes all the articles in order as they are presented in the journal [1].

"Methodology for Investment Evaluation in Electricity Generation Modules in Accordance with the Requirements of the European Union" by L. Vempere, A. Jasevics, L. Zemīte and G. Vempers [2] illustrates that one of the criteria for whole energy system is a stable electricity supply that meets certain technical parameters. In order to achieve synchronous operation of several energy systems, the Commission of the European Union has adopted Regulation No 2016/631 establishing a network code on the applicable network connection requirements for generators. In 2025, the Baltic States plan to integrate into the Energy Systems Association of Continental Europe and work synchronously with the other European Union countries, disconnected from the current BRELL energy systems. The aim is to develop a model for ensuring the safety of electricity systems, including limiting frequency fluctuations at the level allowed for the system, as well as the development of the electricity and ancillary services market and the development of renewable energy sources. An economic analysis to assess which generators need investment and whether their use will provide economic benefits is performed. As a result, it may be recommended that the state can create a priority list, where generators are divided according to their socioeconomic benefits. In cases where the changes are so large that power plants which do not comply with the requirements of the Regulation, regulation on the modernisation of existing plants may be adopted, which means additional investment.

"Estimating the Benefit from Independent Aggregation in the Day-Ahead Market" by K. Baltputnis and Z. Broka [3] provides an assessment of potential benefits from demand response in the day-ahead electricity market if it is offered by independent aggregators. The study is insightful in relation to the development of independent aggregators' regulatory framework in the European countries. The model presented in this study utilises public wholesale market price curve data from the Nord Pool power exchange to simulate market clearing results with introduction of certain amounts of demand response, which, via independent aggregators, compete alongside generation and are able to shift the supply curve. The simulated new market equilibrium point allows estimating the price reduction capability of demand response and the resulting benefits as well as analysing the potential remuneration mechanisms for independent aggregators and implications on their business models. While the results demonstrated a high value from demand response 
during the peak hour, the overall benefits during average price periods were rather low, thus questioning the business case for independent aggregators in the day-ahead market. The proposed approach can be used for further analysis of different independent aggregator compensation mechanisms considering the system-wide benefits demand response brings to the wholesale market.

"Modelling the Future of the Baltic Energy Systems: A Green Scenario" by L. Petrichenko, R. Petrichenko, A. Sauhats,
K. Baltputnis and Z. Broka [4] reflects to the task of long-term strategic planning of the Baltic energy system development. The breadth and complexity of this task is due to the following main factors: $(i)$ the need to model various technologies of power plants, networks, consumers and an interconnected power system of a wide geographic region; (ii) requirement to predict several stochastic processes for many years ahead and (iii) objective functions with many constraints and optimization variables.

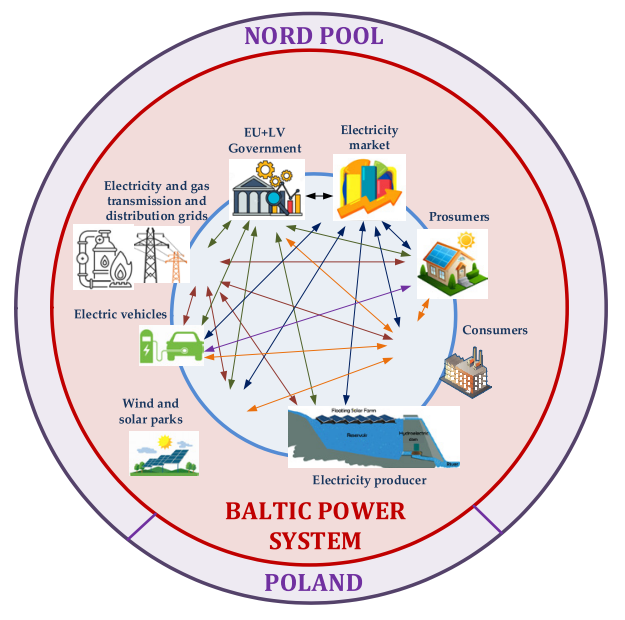

Fig. 1. Overall structure of the power system.

Moreover, there are many participants in the planning and operation of the power system, and their aims often do not coincide. The presence of several agents (deci- sion-makers, see Fig.e 2), leads to further complication of the problem of strategic planning.

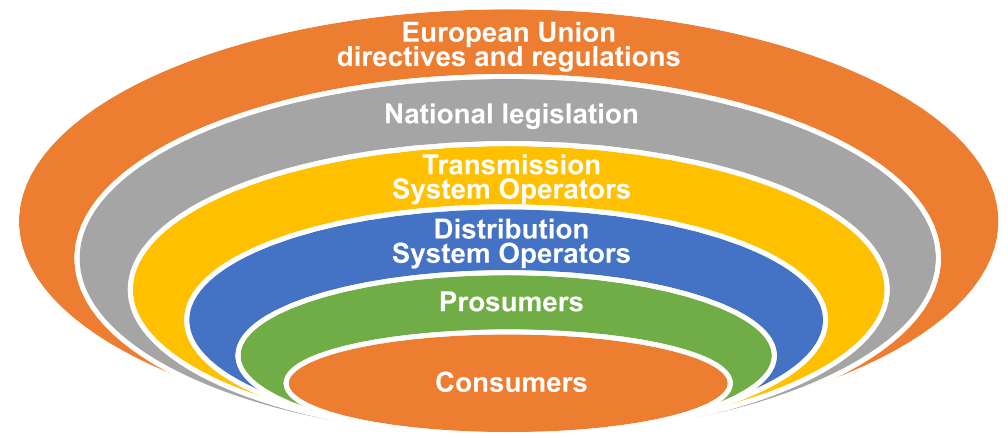

Fig. 2. Decision-makers in power system development planning. 
The decisions are made at various levels, simulating the operation of the future power system and its elements based on a number of forecasts regarding power production and consumption, costs and other parameters. A description of the overall model structure developed this far is provided in conjunction with preliminary input scenarios and produced output. A case study analysis is performed where the resulting electricity generation mix and trade balance with neighbouring countries is assessed under assumptions of notable advancements in installed renewables capacities in the Baltic States by 2050.

"Power Plant Cooperation in District Heating Considering Open Electricity Market" by R. Oleksijs, A. Sauhats and B. Olekshii [5] analyses the possibilities to form a coalition of several electricity and heat suppliers to participate in the district heating market. Cooperation would allow better dispatching the existing energy sources and ensuring a higher total profit for the coalition participants. The objective function for such cooperation is formulated. To optimize the operation of the coalition, mixed integer linear programming is used, considering the constraints of different heat market participants and the need to ensure the heat balance. If any additional profit is made, it is shared among the coalition participants, using the cooperative game theory approach (the Shapley value), which incentivizes the market participants to form a coalition. A numerical case study based on historical prices and consumption is presented.

"Assessment of PV Integration in the Industrial and Residential Sector under Energy Market Conditions" by L. Petrichenko, J. Kozadajevs, R. Petrichenko, O. Ozgonenel, D. Boreiko and A. Dolgicers [6] evaluates the integration of solar photovoltaic technology in the aforementioned sectors. The aim is to determine and compare the payback period for the use of photovoltaic technology in the industrial and residential sectors taking into account the application of optimal load scheduling and the level of self-consumption. In addition, self-consumption has a significant benefit due to high network tariffs. The results show that installation and use of photovoltaic technology is most beneficial to users with high self-consumption. It is also most financially attractive to consumers who are able to invest in photovoltaic directly rather than by taking a loan. Furthermore, the greatest benefit from photovoltaic is gained by employing optimal load scheduling.

"Heat-Pump Optimization Strategies for Participation in Price-Controlled Demand Response in Latvian Electricity Market" by L.Kurevska [7] presents a case study in which six alternative optimization scenarios are compared on the basis of net financial gains. The case study provides insights for energy policy makers and industry representatives who play a considerable role in the integration of demand response services in the energy market framework. The case study design is based on examples from the research of heating, ventilation and air conditioning optimization algorithms. The scenarios have been developed taking into account the main barriers (complexity) and the main motivators (financial gains) for participation in demand response that were identified in previous research in the energy policy field. The case study compares different proxies for forecasting financial gains from switching off heat pumps for a limited time period. The results show that application of a simple algorithm calculating forecast cost savings provides a reduction in the electricity costs of up to $4 \%$.

"Simplified Model for Evaluation of Hydropower Plant Conversion into Pumped Storage Hydropower Plant" by 
S. Kiene and O. Linkevics [8] states that pumped storage hydropower plants currently represent the most mature and widespread storage technology, yet the construction of new facilities is often hampered by the limited choice of suitable sites. An interesting solution is to convert an existing hydropower plant into a pumped storage hydropower plant by building an additional pumping station that pumps water from the lower reservoir during low electricity prices, thus providing additional water for the hydropower units to generate electricity during peak loads. The authors propose a simplified algorithm and a mathematical model to evaluate the operation of hydropower plant based on the historical prices of the Nord Pool market as well as on modelling the possible increase of the daily maximum and minimum electricity price difference in the future. The results show that the difference between the daily maximum and minimum prices at Nord Pool is currently insufficient to ensure recovery of the capital costs of the project. Favourable markets for capital-intensive energy storage projects that use price arbitrage to recover their investments are those with high price volatility. In the future, the increasing share of renewables can bring higher price differences. In addition, results from the simulation of pumped storage hydropower plant operation are then used in the economic model to evaluate feasibility of the proposed conversion.

"Heat Load Numerical Prediction for District Heating System Operational Control" by D. Rusovs, L. Jakovleva, V. Zentins and K. Baltputnis [9] affirms that an advanced control of heat supply for domestic heating needs to be developed, such as the emerging need to plan operation in accordance with an energy market-based environment. To move towards this goal, it is necessary to develop forecasting tools for short- and long-term planning taking into account data about the operation of existing heating systems. This paper considers reallife operational parameters of five different heating networks in Latvia from a period of five years. The application of regression analysis for heating load dependence on outdoor temperature results in the formulation of a normalized slope for the regression curves of the studied systems. The value of this parameter allows describing the performance of particular heating systems. Moreover, a heat load forecasting approach is presented and tested on data from a relatively small district heating system with an average load of $20 \mathrm{MW}$ at an ambient temperature of $0{ }^{\circ} \mathrm{C}$. The deviations of the actual heat load demand from the forecast are evaluated for two testing periods in January 2018. The forecast accuracy is assessed by two parameters - the mean absolute percentage error and the normalized mean bias error.

"A Linearized Numerical Solution for Steady-State Simulations of Gas Networks" by I. Zalitis, A. Dolgicers, L. Zemite, S. Ganter, V. Kopustinskas, B. Vamanu, I. Bode and J. Kozadajevs [10] examines risks and resilience analysis and potentially operational planning for different gas transmission systems or other purposes. The changes of gas transmission system brought diversification of gas suppliers, implementation of new interconnections with the European gas transmission system. The developed method combines the linearized hydraulic conductivity approach with a technique derived from linear electrical circuit analysis and an additional pressure change term for modelling of active non-pipeline elements of different gas transmission systems. Operational limits of compressors and pressure regulators and changes of compressibility factor and gas viscosity based on the gas composi- 
tion, temperature and pressure are also considered in the model. Results obtained from a validation case study performed for the proposed method are presented.

"CHPP Operation Mode Optimization at Electricity and Gas Market Conditions Using a Genetic Algorithm" by J. Kozadajevs, A. Dolgicers and D. Boreiko [11] presents an operational planning optimization approach using a genetic algorithm for cogeneration power plants in urban heat supply areas. For efficient production planning in the liberalized power markets, it is paramount is to determine the optimal strategies over a time horizon. Solution of an optimization task of such complexity requires a well-crafted set of tailored modelling, simulation, optimization, and forecasting tools. A number of production units, such as gas turbines, steam turbines, heatonly boilers and thermal storages, reflected in the optimization model, are utilised to increase flexibility of generation.

"The Natural Gas as a Sustainable Fuel Alternative in Latvia" by J. Savickis, A. Ansone, L. Zemite, I. Bode, L. Jansons, N. Zeltins, A. Koposovs, L. Vempere and E. Dzelzitis [12] states that compressed natural gas and biomethane as well as liquid natural gas may be more suitable alternatives to conventional fuels for the decarbonisation of the transport sector in cities and other densely populated areas. On the basis of this mobility implementation experience in other European countries, the article provides an analytical insight into three basic development strategies of mobility in Latvia in this decade, with a particular focus on the prospects of simultaneous use of natural gas and biomethane as sources of compressed and liquid natural gas. The compressed natural gas fleet can cover private, business and municipal transport categories, and can be used both in places where natural gas pipeline deliveries are available and where biomethane is produced and supplied on site, at the biogas/biomethane production facilities. Biomethane can perfectly blend with natural gas at any given proportion and thus ensure decarbonisation of the natural gas network and the transport sector simultaneously. Liquefied natural gas can be used for bringing gas to regions where pipeline supply infrastructure is historically absent, limited or underdeveloped. The prospects for the use of liquefied natural gas there in both medium-term and long-term perspective must be carefully evaluated, especially with regard to the emerging bunkering business in the Baltic Sea region.

Comparing the aims of the projects described in Section 2 and the results of the research described in Section 3, evidently, only part of the initially outlined tasks have been presented. Indeed, as the research projects are still ongoing, the remaining tasks are set for completion by 2021. On the other hand, a significant number of journal articles and papers in conference proceedings have been published beforehand, showcasing the prior results of the outlined projects. References to some of these publications can be found in the related articles of this special issue.

"The Natural Gas Supply of the Latvian Municipality during the Local Energy Crisis" by L. Zemite, E. Nevercika, L. Jansons, I. Bode, A. Koposovs, N. Kondrahins and A. Jasevics [13] treats the natural gas system as the essential element of the Latvian and the Baltic energy supply. Gas system disruption can seriously impact the national economy and energy security of our country. The article focuses on efficiency of the natural gas supply to the Latvian municipalities, when a local energy crisis is announced. Among other issues, it covers various potential vulnerability factors that may cause the natural gas supply shortages or disruption periods of 
different length for a wide spectrum of the Latvian natural gas consumers - starting with households and finishing with large industrial consumers and energy producers. A legislative framework analysis along with emergency natural gas supply models has been proposed and reviewed as well, taking into account the actual distribution of the natural gas consumption among urban energy consumers.

"The Creation of the Integrated Natural Gas Market in the Baltic Region and its Legal Implications" by L. Zemite, A. Ansone, L. Jansons, I. Bode, E. Dzelzitis, A. Selickis, A. Romanovs and L. Vempere [14] examines natural gas as the cleanest of conventional fossil fuels. In a mid-term perspective, natural gas is considered an important low-carbon energy resource to ensure smooth transition to carbon neutrality both on the national and the regional scale. The main milestones on the way to the creation of a common natural gas market in the Baltic States and Finland, with emphasis on its legislative implications and the possibility of market expansion in the future, are addressed. There are also expectations to expand the common Baltic-Finnish natural gas market westwards after the completion of the natural gas interconnection between Lithuania and Poland. As a result, Poland could join the market platform as a partner and as a crucial route of alternative natural gas deliveries to the Baltic States and Finland. In a long-term perspective, the creation of an integrated regional natural gas market will stimulate the price transparency, strengthen security of the natural gas supply and improve market liquidity in the Baltic region.

"Analysis of the Role of Latvian Natural Gas Network for the Use of Future Energy Systems: Hydrogen from RES" by J. Kleperis, D. Boss, A. Mezulis, L. Zemite, P. Lesnicenoks and A. Knoks and
I. Dimanta [15] shows that carbon-containing fuels and transfer to carbon-neutral fuel are necessary; therefore, hydrogen may be the answer to achieve the overall European targets. As Latvia has renewable energy sources, it is possible to ensure some production, storage and use of hydrogen. In the article, clear guidelines for Latvia have been investigated. The existing natural gas network may be used for two tasks: largescale hydrogen transportation and decarbonisation of the natural gas network. To open the natural gas networks for hydrogen, the first evaluations are made and a possible scenario for hydrogen implementation in the network supplying household consumers is analysed to evaluate decarbonisation with the overarching goal of carbon neutrality.

"A Review: The Energy Poverty Issue in the European Union and Latvia" by D. Zalostiba and D. Kiselovs [16] is devoted to the analysis of the energy poverty problem. Low level of income, high energy prices/costs and low energy efficiency are the primary factors that characterise energy poverty. The availability and affordability of energy have a direct impact on the quality of life and well-being of society and individuals; the energy sector as a whole as well as areas such as healthcare, consumption and housing sectors are also affected. Although there are no unified definition of energy poverty and no harmonized methodology to assess it, energy poverty has been recognised as a social priority at the European level and embedded in the framework of the "Third Energy Package". To estimate the energy poverty in Latvia, the way energy poverty is currently defined and measured in other countries has been reviewed. Taking into account the available data and information, the analysis of energy poverty has been conducted in three characterising dimensions: low income, high 
costs of energy services and unsatisfactory housing conditions, by using statistical data as well as the indicators recommended by the European Union Energy Poverty Observatory, and compared with the European Union average values. Since the implemen- tation of policy measures plays a vital role in tackling energy poverty and protecting the most vulnerable social groups, the good practice and measures implemented in individual Member States, including Latvia, have been studied.

\section{CONCLUSIONS}

The energy transition process is already in full swing. Dramatic changes in recent decades have occurred in the energy systems of the Baltic countries as well: the number, capacity and production of wind farms and solar power plants are growing rapidly; the role of cogeneration plants has increased; the cross-border connections have improved; the energy demand and prices have changed rapidly and significantly. Therefore, it is necessary to understand and predict the functioning and performance of individual components of the power system. It promotes the development of optimization models and analysis tools for the adequacy, security, reliability and stability of the Baltic energy system in the future.
The results of the articles in this special issue show that the energy transition and the use of new technologies should be supported by all the participants in the energy industry value chain: energy generation, transmission, supply, consumption and policy-making. To support the decision-making process, new technologies and new planning and control methods as well as new software products are required. All changes should be focused on reducing the use of fossil fuels and $\mathrm{CO}_{2}$ emissions while maintaining both economic feasibility and technical security; the upcoming changes should contribute to each country's energy independence and ultimately bring overall societal benefits.

\section{REFERENCES}

1. Sauhats, A., Broka, Z., \& Baltputnis, K. (2021). Energy Transition of the Baltic States: Problems and Solutions. Latvian Journal of Physics and Technical Sciences, 58 (3), 3-14. DOI: https://doi.org/10.2478/ lpts-2021-0013

2. Vempere, L., Jasevics, A., Zemite, L., \& Vempers, G. (2021). Methodology for Investment Evaluation in Electricity Generation Modules in Accordance with the Requirements of the European Union. Latvian Journal of Physics and Technical Sciences, 58 (3), 15-31. DOI: https://doi. org/10.2478/lpts-2021-0014
3. Baltputnis, K., \& Broka, Z. (2021). Estimating the Benefit from Independent Aggregation in the Day-Ahead Market. Latvian Journal of Physics and Technical Sciences, 58 (3), 32-46. DOI: https://doi. org/10.2478/lpts-2021-0015

4. Petrichenko, L., Petrichenko, R., Sauhats, A., Baltputnis, K., \& Broka, Z. (2021). Modelling the Future of the Baltic Energy Systems: A Green Scenario. Latvian Journal of Physics and Technical Sciences, 58 (3), 47-65. DOI: https://doi.org/10.2478/ lpts-2021-0016 
5. Oleksijs, R., Sauhats, A., \& Olekshii, B. (2021). Power Plant Cooperation in District Heating Considering Open Electricity Market. Latvian Journal of Physics and Technical Sciences, 58 (3), 66-81. DOI: https://doi.org/10.2478/lpts-2021-0017

6. Petrichenko, L., Kozadajevs, J., Petrichenko, R., Ozgonenel, O., Boreiko, D., \& Dolgicers, A. (2021). Assessment of PV Integration in the Industrial and Residential Sector under Energy Market Conditions. Latvian Journal of Physics and Technical Sciences, 58 (3), 82-97. DOI: https://doi.org/10.2478/lpts2021-0018

7. Kurevska, L. (2021). Heat-Pump Optimization Strategies for Participation in Price-Controlled Demand Response in Latvian Electricity Market. Latvian Journal of Physics and Technical Sciences, 58 (3), 98-107. DOI: https://doi.org/10.2478/lpts2021-0019

8. Kiene, S., \& Linkevics, O. (2021). Simplified Model for Evaluation of Hydropower Plant Conversion into Pumped Storage Hydropower Plant. Latvian Journal of Physics and Technical Sciences, 58 (3), 108-120. DOI: https://doi.org/10.2478/lpts2021-0020

9. Rusovs, D., Jakovleva, L., Zentins, V., \& Baltputnis, K. (2021). Heat Load Numerical Prediction for District Heating System Operational Control. Latvian Journal of Physics and Technical Sciences, 58 (3), 121-136. DOI: https://doi.org/10.2478/lpts2021-0021

10. Zalitis, I., Dolgicers, A., Zemite, L., Ganter, S., Kopustinskas, V., Vamanu, B. ... \& Kozadajevs, J. (2021). A Linearized Numerical Solution for Steady-State Simulations of Gas Networks. Latvian Journal of Physics and Technical Sciences, 58 (3), 137-153. DOI: https://doi.org/ 10.2478/lpts-2021-0022
11. Kozadajevs, J., Dolgicers, A., \& Boreiko, D. (2021). CHPP Operation Mode Optimization at Electricity and Gas Market Conditions, Using a Genetic Algorithm. Latvian Journal of Physics and Technical Sciences, 58 (3), 154-168. DOI: https://doi. org/10.2478/lpts-2021-0023

12. Savickis, J., Ansone, A., Zemite, L., Bode, I., Jansons, L., Zeltins, N. ... \& Dzelzitis, E. (2021). The Natural Gas as a Sustainable Fuel Alternative in Latvia. Latvian Journal of Physics and Technical Sciences, 58 (3), 169-185. DOI: https://doi.org/10.2478/lpts2021-0024

13. Zemite, L., Nevercika, E., Jansons, L., Bode, I., Koposovs, A., Kondrahins, N., \& Jasevics, A. (2021). The Natural Gas Supply of the Latvian Municipality during the Local Energy Crisis. Latvian Journal of Physics and Technical Sciences, 58 (3), 186-200. DOI: https://doi.org/10.2478/lpts-2021-0025

14. Zemite, L., Ansone, A., Jansons, L., Bode, I., Dzelzitis, E., Selickis, A. \& Vempere, L. (2021). The Creation of the Integrated Natural Gas Market in the Baltic Region and its Legal Implications. Latvian Journal of Physics and Technical Sciences, 58 (3), 201-213. DOI: https://doi.org/10.2478/lpts2021-0026

15. Kleperis, J., Boss, D., Mezulis, A., Zemite, L., Lesnicenoks, P., Knoks, A., \& Dimanta, I. (2021). Analysis of the Role of Latvian Natural Gas Network for the Use of Future Energy Systems: Hydrogen from RES. Latvian Journal of Physics and Technical Sciences, 58 (3), 214-226. DOI: https://doi. org/10.2478/lpts-2021-0027

16. Zalostiba, D., \& Kiselovs, D. (2021). A Review: The Energy Poverty Issue in the European Union and Latvia. Latvian Journal of Physics and Technical Sciences, 58 (3), 227-248. DOI: https://doi. org/10.2478/lpts-2021-0028 